\title{
Randomised controlled study of postinjection immobilisation after intra-articular glucocorticoid treatment for wrist synovitis
}

\author{
T Weitoft, L Rönnblom
}

Background: Intra-articular glucocorticoid treatment is frequently used in arthritic disorders. Postinjection rest has been shown to improve the outcome of knee injections.

Objective: To investigate whether better treatment results might also be achieved by a similar postinjection regimen for the wrist, which is non-weightbearing.

Methods: 117 patients with rheumatoid arthritis and wrist synovitis were treated with intra-articular glucocorticoid injections. The patients were randomly allocated to 48 hour postinjection immobilisation in elastic wrist orthoses $(n=58)$ or to normal postinjection activity $(n=59)$. The primary end point was relapse of synovitis. In addition, joint circumference, pain, function, range of movement, and grip strength were followed up during six months.

Results: 24 relapses occurred in the orthoses group and 14 in the active group $(p=0.056)$. The secondary measure showed no statistically significant differences between the groups.

Conclusion: The use of elastic wrist orthoses as a postinjection regimen does not improve the outcome of intra-articular glucocorticoid treatment for wrist synovitis. Results achieved in studies on knees should not be generalised to other joints, and postinjection recommendations should differ depending on the joint treated.

1: ntra-articular glucocorticoid treatment is frequently used to relieve arthritic symptoms, and it has become an important tool in the treatment of rheumatic disorders. Previous studies have shown that a 24-48 hour postinjection bed rest of the knee, a weightbearing joint, is beneficial. ${ }^{2}$ In contrast, the results for non-weightbearing joints are conflicting. Inclusion of only a small number of patients and major differences in study design make it difficult to draw conclusions from those

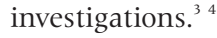

Most rheumatologists advise their patients to rest the injected joints (Kjällman M, Swedish Society of Medicine presentation 1989), ${ }^{5}$ but the recommendations differ. This is probably because there is insufficient scientific documentation about postinjection immobilisation of non-weightbearing joints.

In this study we investigated the clinical outcome of intraarticular glucocorticoid treatment of the wrist and asked whether 48 hour immobilisation in elastic wrist orthoses might improve the treatment result. The primary end point was relapse of wrist synovitis, but a number of secondary clinical measures were also followed.

The result of this study may be applied directly to clinical practice and to future recommendations for a postinjection regimen for wrist synovitis.

\begin{tabular}{|c|c|}
\hline Parameter & Method \\
\hline Range of movement & $\begin{array}{l}\text { The range of active motion, as measured } \\
\text { between the fifth metacarpal bone and the } \\
\text { forearm resting on a table by a Medema } \\
\text { goniometer }\end{array}$ \\
\hline Joint circumference & $\begin{array}{l}\text { The wrist circumference just distal to the } \\
\text { styloid process }\end{array}$ \\
\hline Grip strength & $\begin{array}{l}\text { Measured electronically with a Grippit } \\
\text { instrument, with a peak value and a mean } \\
\text { value of a } 10 \text { second force }{ }^{10}\end{array}$ \\
\hline Function & $\begin{array}{l}\text { Self evaluation with a six question } \\
\text { questionnaire, according to the patient rated } \\
\text { wrist evaluation (PRWE). } 11 \text { All answers were } \\
\text { given on a } 10 \text { point scale and consequently } \\
\text { the maximum score was } 60\end{array}$ \\
\hline Pain & $\begin{array}{l}\text { Self evaluation (five questions) according to } \\
\text { PRWE, which means a maximum pain score } \\
\text { of } 50\end{array}$ \\
\hline
\end{tabular}

\section{METHODS}

Consecutive patients at the outpatient rheumatology departments in Gävle and Uppsala, fulfilling the 1987 American College of Rheumatology criteria for rheumatoid arthritis ${ }^{7}$ with signs and symptoms of wrist synovitis (heat, pain, tenderness, and swelling), were invited to participate in the study. Patients in functional class 4 according to Steinbrocker, ${ }^{8}$ patients with major hand deformities or planning hand surgery, patients with daily oral glucocorticoid treatment corresponding to more than $7.5 \mathrm{mg}$ prednisone, and patients who had received an intra-articular glucocorticoid injection in the treated wrist in the past three months were excluded.

Patients gave their informed consent, and data on the characteristics of the patients were collected. Baseline disease activity was assessed by the erythrocyte sedimentation rate and the serum $\mathrm{C}$ reactive protein level, and general function by a Health Assessment Questionnaire (HAQ), slightly modified by Ekdahl and coworkers. ${ }^{9}$

Joint circumference, grip strength, pain, function, and range of movement were measured. Table 1 indicates the measurement methods used.

All wrists were treated by the same doctor (TW) with $10 \mathrm{mg}$ triamcinolone hexacetonide using the same injection procedure in all cases. The needle size used was $0.6 \times 25 \mathrm{~mm}$.

The treated joints were randomly allocated to 48 hours' immobilisation in elastic wrist orthoses (Elcross Carpi Flexi,

Abbreviations: DMARDs, disease modifying antirheumatic drugs; $H A Q$, Health Assessment Questionnaire; PRWE, patient rated wrist evaluation 
Table 2 Patient characteristics

\begin{tabular}{|c|c|c|c|}
\hline & $\begin{array}{l}48 \text { Hour orthoses } \\
\text { immobilisation } \\
(n=58)\end{array}$ & $\begin{array}{l}\text { Normal activity } \\
(\mathrm{n}=59)\end{array}$ & $\mathrm{p}$ Value \\
\hline Age $^{*}$ ( years), median (range) & $61.5(28-86)$ & $61(28-86)$ & NS \\
\hline Sext (male/female) & $9 / 49$ & $14 / 45$ & NS \\
\hline Duration of disease*(years), median (range) & $7(0-38)$ & $7(0-63)$ & NS \\
\hline DMARD treatment $\dagger$ & 47 & 51 & NS \\
\hline Systemic corticosteroid treatment $\dagger$ & 25 & 18 & NS \\
\hline Injection on dominant side $\dagger$ & 35 & 37 & NS \\
\hline General function $(\mathrm{HAQ}) \dagger$, median (range) & $1.25(0.13-2.75)$ & $1.13(0.13-2.25)$ & NS \\
\hline Erythrocyte sedimentation rate $(\mathrm{mm} / 1 \mathrm{st} \mathrm{h})^{*}$, median (range) & $35(6-106)$ & $32(2-112)$ & NS \\
\hline$C^{\prime}$ reactive protein $(\mathrm{mmol} / \mathrm{l})^{*}$, median (range) & $21(5-220)$ & $23(5-192)$ & NS \\
\hline Wrist pain (PRWE) $\ddagger$, mean (SD) & $32.7(9.1)$ & $31.4(8.6)$ & NS \\
\hline Wrist function (PRWE) $\ddagger$, mean (SD) & $38.4(12.3)$ & 35.7 (11.5) & NS \\
\hline Wrist joint circumference $(\mathrm{mm})$, mean (SD) & $177.1(16.1)$ & $175.7(15.1)$ & NS \\
\hline Range of wrist movement $\left({ }^{\circ}\right)$, mean (SD) & $82.9(23.0)$ & $85.8(20.9)$ & NS \\
\hline Grip strength $\max (N)^{*}$, median (range) & $55(0-326)$ & $67(25-206)$ & NS \\
\hline Grip strength mean during $10 \mathrm{sec}(\mathrm{N})^{*}$, median (range) & $42(0-283)$ & $51(14-183)$ & NS \\
\hline
\end{tabular}

Camp Scandinavia) or to normal activity. The clinical measurements were also made after one week, three and six months. The patients were told to contact the rheumatology departments if signs and symptoms from the treated wrist recurred. If so, the joint was re-examined and if wrist synovitis could be confirmed, a relapse was recorded. The patients could not have both wrists included in the study.

The study was approved by the ethics committee at the medical faculty of Uppsala University.

A total of 117 patients were included in the study, and table 2 presents their characteristics. Both groups were treated during the observation period with disease modifying antirheumatic drugs (DMARDs) according to the routines in the clinical practice. During the six month observation period the DMARD treatment was changed for 12 patients in the orthoses group and for eight patients in the active group.

Patients with a relapse of arthritis and another wrist injection were excluded from later follow up visits. At the three month visit 47 patients were measured in the immobilisation group and 52 in the active group, and at the six month visit 38 and 43 patients, respectively.

For a comparison of the baseline data between the groups the Mann-Whitney $U$ test, Student's $t$ test, and $\chi^{2}$ test were used when appropriate. The relapse rates are shown as a Kaplan-Maier curve and a log rank test was used to calculate

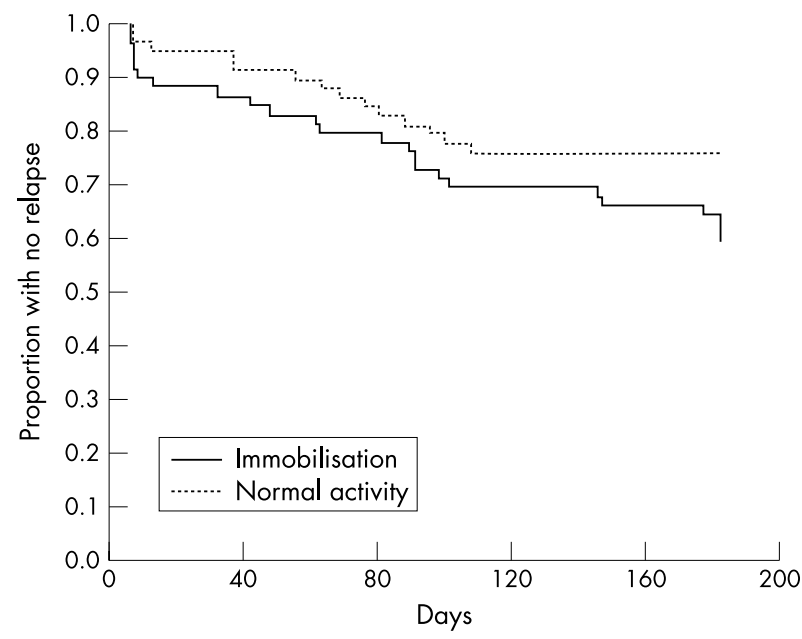

Figure 1 Duration of the therapeutic effect after glucocorticoid injection in the wrist with or without immobilisation in elastic wrist orthoses. the statistical difference between the curves. A $\chi^{2}$ test was used to test for significance between the proportions relapsing in the groups at the end of the study. To test for a difference in the mean change of the secondary measures after one week, three months, and six months, an analysis of covariance with baseline level as covariate was performed. A p value $<0.05$ was considered significant, but for wrist measurement results a Bonferroni correction $(\mathrm{p}<0.01)$ was performed. All tests were two tailed.

The statistical analysis was made by the statistical computer software program SPSS, version 11.0 for Windows NT.

\section{RESULTS}

The Kaplan-Maier curves showed a non-significant trend to more relapses in the immobilisation group $(\mathrm{p}=0.0694)$ ( fig l). During the study 24 relapses occurred in the group with orthoses and 14 in the group with normal postinjection activity $(\mathrm{p}=0.056)$.

No significant differences in the changes of the secondary measures were found between the groups after one week, three and six months (data not shown).

\section{DISCUSSION}

Clinical studies on the outcome of intra-articular glucocorticoid injection treatment are mostly performed on knees. Consequently, most knowledge of the method concerns synovitis of the knee. Other joints have different construction and function, and may therefore respond differently. Therefore, we embarked on the present study to examine the effect of immobilisation after intra-articular corticosteroid injection of the wrist. A splint and a mitella would have provided the most complete rest, but we chose 48 hour postinjection immobilisation in elastic wrist orthoses, because this method is used in clinical practice. ${ }^{32}$ To the best of our knowledge this is the largest prospective glucocorticoid injection study performed on a joint other than the knee.

To our surprise, we noted $70 \%$ more relapses in the orthoses group than in the subjects with normal activity after injection. However, the difference in the relapse rate between the two groups did not reach statistical significance, which may be because of the lower number of relapses among the patients than we expected. Thus, our study may suffer from a type II error, but despite this the data suggest that normal activity should be preferred before immobilisation after glucocorticoid injection in the wrist.

The result of this study is not consistent with the data obtained after knee injections, and several possible explanations for the discrepancy may be considered. 
Firstly, loading and exercise are supposed to increase the glucocorticoid absorption and decrease the following local anti-inflammatory effect. In the knee, the loading related absorption of the glucocorticoid should be much greater than in the non-weightbearing wrist.

Secondly, it has been suggested that the area of the inflamed synovium determines the degree of steroid resorption..$^{13}$ As the wrist has a much smaller synovial surface than the knee, the glucocorticoid resorption should also be smaller in the wrist joint. The influence of immobilisation might therefore be of minor importance.

Furthermore, wrist movement may be important to spread the substance around the joint cavity and into connecting joints as well as tendon sheaths.

In summary, as the use of elastic orthoses after intraarticular glucocorticoid treatment for wrist synovitis does not improve the outcome, a routine of postinjection rest is not recommended. Because results obtained in studies on one specific joint cannot be generalised to other joints, further studies on different joints and their response to postinjection rest are needed. Such studies will lead to more adequate recommendations for postinjection treatment, which obviously should differ depending on the joint that is being treated.

\section{ACKNOWLEDGEMENTS}

We thank Åsa Olsson, Britt-Inger Nilsson, Helena Sjösten, and Lotta Sjöberg, nurses at the rheumatology departments in Gävle and Uppsala, for helping us with wrist measurements. Hans Högberg, FOU-forum Gävleborg, has been of great help with the statistical analysis.

The study was supported by grants from FOU-forum Gävleborg, Reumatikerförbundet, Konung Gustaf den V:s 80-årsfond, Camp Scandinavia, and Wyeth-Lederle.

\section{Authors' affiliations}

T Weitoft, Section of Rheumatology, Department of Internal Medicine, Gävle County Hospital, Sweden

T Weitoft, L Rönnblom, Section of Rheumatology, Department of Internal Medicine, Uppsala University Hospital, Sweden

Correspondence to: Dr T Weitoft, Section of Rheumatology, Department of Internal Medicine, Gävle County Hospital, 80187 Gävle, Sweden; tomas.weitoft@lg.se

Accepted 17 February 2003

\section{REFERENCES}

1 Chakravarty K, Pharoah PDP, Scott DGI. A randomised controlled study of postinjection rest following intra-articular steroid therapy for knee synovitis. Br J Rheumatol 1994;33:464-8.

2 Neustadt DH. Synovitis of the knee. Effects of postinjection rest. Clin Rheumatol Pract 1985;3:65-8.

3 Chatham W, Williams G, Moreland L, Parker JW, Ross C, Alarcón SG, et al. Intra-articular corticosteroid injections: should we rest the joints? Arthritis Care Res 1989;2:70-4.

4 McCarty DJ. Treatment of rheumatoid joint inflammation with McCarty DJ. Treatment of rheumatoid joint inflammation with
Triamcinolone hexacetonide. Arthritis Rheum 1972;15:157-73.

5 Haslock L, Macfarlane D, Speed C. Intra-articular and soft tissue injections: a survey of current practice. Br J Rheumatol 1995;34:449-52.

6 Centeno LM, Moore ME. Preferred intraarticular corticosteroids and associated practice. A survey of members in the American College of Rheumatology. Arthritis Care Res 1994;7:151-5.

7 Arnett FC, Edworthy SM, Bloch DA, Shane DA, Fries JF, Cooper NS, et al. The American Rheumatism Association 1987 revised criteria for the classification of rheumatoid arthritis. Arthritis Rheum 1988;31:315-24.

8 Stassification of rheumatoid arthritis. Arthritis Rheum 1988;31:315-24. Steinbrocker O, Traeger CH, Betterman RC. Thera
rheumatoid arthritis. JAMA 1949;140:659-62.

9 Ekdahl C, Eberhardt K, Andersson SI, Svensson B. Assessing disability in patients with rheumatoid arthritis. Scand J Rheumatol 1988;17:263-71.

10 Nordenskiöld UM, Grimby E. Grip force in patients with rheumatoid arthritis and fibromyalgia and in healthy patients. Scand J Rheumatol 1993;22;14-19.

11 MacDermid JC, Turgeon T, Richards RS, Beadle M, Roth JH. Patient rating of wrist pain and disability: a reliable and valid measurement tool. Orthop Trauma 1998;8:577-86

12 Hunter JA, Blyth TH. A risk-benefit assessment of intra-articular corticosteroids in rheumatic disorders. Drug Saf 1999;21:353-65

13 Armstrong RD, English J, Gibson T, Chakraborty J, Marks V. Serum methylprednisolone levels following intra-articular injection of methylprednisolone acetate. Ann Rheum Dis 1981;40:571-4. 